\title{
Cardiovascular Risk Factor Control and Lifestyle Factors in Young to Middle-Aged Adults with Newly Diagnosed Obstructive Coronary Artery Disease
}

\author{
Michael S. Garshick ${ }^{a}$ Georgeta D. Vaidean ${ }^{a, b} \quad$ Anish Vani $^{a}$ \\ James A. Underberg ${ }^{a}$ Jonathan D. Newman ${ }^{a}$ Jeffrey S. Berger ${ }^{a}$ \\ Edward A. Fisher ${ }^{\mathrm{a}}$ Eugenia Gianos ${ }^{c}$ \\ ${ }^{a}$ Center for the Prevention of Cardiovascular Disease, New York University Langone Health, New York City, NY, USA; \\ ${ }^{b}$ Fairleigh Dickinson University School of Pharmacy and Health Sciences, Florham Park, NJ, USA; 'Department of \\ Cardiology, Lenox Hill Hospital, Northwell Health, New York, NY, USA
}

\section{Keywords}

Prevention · Preventive cardiology · Cardiovascular risk factors · Accelerated atherosclerosis

\begin{abstract}
Background: While progress in the prevention of cardiovascular disease (CVD) has been noted over the past several decades, there are still those who develop CVD earlier in life than others. Objective: We investigated traditional and lifestyle CVD risk factors in young to middle-aged patients compared to older ones with obstructive coronary artery disease (CAD). Methods: A retrospective analysis of patients with a new diagnosis of obstructive CAD undergoing coronary intervention was performed. Young to middle-aged patients were defined as those in the youngest quartile ( $n=$ 281 , mean age $50 \pm 6$ years, $81 \%$ male) compared to the other three older quartiles combined ( $n=799$, mean age 69 \pm 7.5 years, $71 \%$ male). Obstructive CAD was determined by angiography. Results: Young to middle-aged patients compared to older ones were more likely to be male $(p<0.01)$, smokers ( 21 vs. $9 \%, p<0.001$ ), and have a higher body mass index (31 \pm 6 vs. $\left.29 \pm 6 \mathrm{~kg} / \mathrm{m}^{2}, p<0.001\right)$. Younger patients
\end{abstract}

were less likely to eat fruits, vegetables, and fish and had fewer controlled CVD risk factors $(2.7 \pm 1.2$ vs. $3.0 \pm 1.0, p<$ $0.001)$. Compared to older patients, higher levels of psychological stress (aOR 1.6, 95\% Cl 1.1-2.4), financial stress (aOR $1.8,95 \% \mathrm{Cl} 1.3-2.5$ ), and low functional capacity (aOR 3.3, 95\% Cl 2.4-4.5) were noted in the young to middle-aged population as well. Conclusion: Lifestyle in addition to traditional CVD risk factors should be taken into account when evaluating risk for development of CVD in a younger population.

๑) 2019 S. Karger AG, Basel

\section{Introduction}

During the last three decades, primary and secondary prevention efforts have led to a considerable decline in cardiovascular disease (CVD) and coronary heart disease incidence and mortality in the US [1]. However, recently the rate of decline in age-adjusted CVD and coronary heart disease mortality rates has slowed [2]. Particularly concerning are the trends of acute myocardial infarction hospitalization and mortality rates among young to mid-

\section{KARGER}

(c) 2019 S. Karger AG, Basel

E-Mail karger@karger.com

www.karger.com/crd
Michael S. Garshick

Center for the Prevention of Cardiovascular Disease

New York University Langone Health, 435 East 30th Street, 7th Floor

New York City, NY 10016 (USA)

E-Mail Michael.garshick@ nyumc.org 
dle-aged adults ( $<55$ years of age), where rates have not declined over the past decade [3].

In line with this, studies in the young to middle-aged US population have documented an increased prevalence of obesity, diabetes mellitus (DM), and stagnation in the improvement of lipid levels, all in the setting of suboptimal lifestyle behaviors such as poor diet, decreased physical activity, and increased rates of smoking $[1,4]$. These CVD trends in young to middle-aged adults suggest the need for improved identification and treatment of highrisk individuals. Furthermore, the currently employed CVD risk assessment tools focusing on 10-year CVD risk calculation are heavily age-weighted and have been shown to underestimate CVD risk in the young to middle-aged populations $[5,6]$.

The main objective of this analysis was to assess CVD risk factor control and lifestyle factors associated with a new diagnosis of obstructive coronary artery disease (CAD) in young to middle-aged patients compared to older ones undergoing cardiovascular $(\mathrm{CV})$ procedures. Additionally, because lifestyle factors are not components of a traditional cardiac risk score for primary prevention risk stratification, recognizing and clarifying these factors may further guide CVD risk assessment and targeted preventive measures for young to middle-aged patients with less favorable trends in CVD outcomes [7$10]$.

\section{Methods}

The New York University Langone Health Preventive Cardiology Inpatient Consult Service [11, 12] was established in 2010 as an effort to optimize CVD risk factor control of patients undergoing elective $\mathrm{CV}$ procedures. We performed a retrospective analysis of patients undergoing preventive cardiology consultation after elective coronary angiography along with coronary intervention from November 2010 through October 2017 (entire cohort, $n=$ 2,385 , average age $66.5 \pm 25$ years, $75 \%$ male, $67 \%$ white). We excluded patients with a pre-existing diagnosis of CVD defined as a self-reported or chart diagnosis of CVD (e.g., prior history of myocardial infarction $[\mathrm{MI}]$, coronary or lower extremity intervention). A total of 1,088 patients (average age $64 \pm 11$ years, $74 \%$ male, $68 \%$ white) met these criteria.

Demographics, anthropometrics, past medical history, including hypertension (HTN), hypercholesterolemia (HLD), DM, and medications were obtained by chart review, administrative ICD$9 / 10$ codes, and by direct patient interview conducted during the CVD prevention consultation immediately post coronary angiography. Blood pressure was recorded at the time of the prevention consult interview, after coronary angiography. All laboratory data were recorded immediately post coronary angiography or within 2 weeks prior to the procedure (lipids, creatinine, hemoglobin Alc $[\mathrm{HbA1c}]$ ). A new diagnosis of obstructive CAD was determined as undergoing a coronary intervention or having $\geq 1$ coronary lesion with $\geq 70 \%$ stenosis ( $\geq 50 \%$ for left main) on angiography and not having pre-existing CVD (as defined above).

Traditional CVD risk factors were considered to be those included in CVD risk scoring systems (HTN, HLD, DM, smoking) as well as body mass index (BMI). Lifestyle CVD risk factors included dietary intake, functional capacity, and levels of stress (both financial and personal) and were assessed according to a previously published protocol [11]. Briefly, diet was assessed using an in-house food frequency questionnaire that focused on daily fruit, vegetable, sweetened beverage, and weekly fish intake as noted in the American Heart Association (AHA) guideline recommendations [13]. Physical activity was assessed by relative functional capacity defined by the Duke Activity Status Index (DASI) [14]. The DASI consists of 12 questions to evaluate the ability to perform a variety of physical activities and ranges from a score of 0 to 58.2 (high functional capacity). Each DASI score was converted into age- and sex-specific metabolic equivalents (METS), referenced to predicted METS for age and sex and then reported as the actual METS/predicted METs $\times 100$. Predicted METS levels $\geq 85 \%$ are considered an ideal level of functional capacity, where $<85 \%$ is considered an intermediate or poor level [14]. Psychosocial questions were adapted from INTERHEART study methodology and included questions on feelings of depression, in addition to levels of financial and personal stress [11]. Significant financial stress was defined as frequent feelings of moderate or severe financial stress (as compared to little or none), while significant personal stress was defined as several or permanent periods of stress (as compared to never or some periods).

The degree to which CVD risk factors (both traditional and lifestyle) were controlled was defined as "CV health factors at goal" and determined through recommendations set for the primary prevention of CVD by the AHA to follow "Life's Simple 7" [4, 15]. This included a BMI $<25 \mathrm{~kg} / \mathrm{m}^{2}$, systolic blood pressure $<120 \mathrm{~mm}$ $\mathrm{Hg}$, total cholesterol $<200 \mathrm{mg} / \mathrm{dL}$, healthy eating habits ( 2 out of 3 of either: $\geq 4.5$ cups/day of fruits and/or vegetables, $\geq 2$ servings fish/week, $<8$ ounces of sweetened beverages/day), nonsmoking status, $\mathrm{HbA1c}<7.0 \%$, or physical activity $\geq 85 \%$ METS of predicted activity for age and gender.

In order to specifically investigate "younger" patients, age was categorized into quartiles across the entire cohort of patients presenting with a new diagnosis of obstructive CAD. Younger patients in the cohort were defined as the first quartile (25-57 years of age) - termed young to middle aged. This was compared to the last three quartiles combined (58-96 years of age).

Descriptive analysis of all patient characteristics comparing the first to the remaining three quartiles was performed with a $t$ test or Mann-Whitney U test for continuous variables as appropriate and a $\chi^{2}$ test for categorical variables. Logistic regression was used to assess lifestyle factors associated with younger age at first presentation of obstructive CAD (dependent variable). Multivariable models were adjusted for sex, obesity, HTN, HLD, active smoking, and DM. Interaction terms were tested between each lifestyle factor and sex by creating a cross-product term in the multivariable model. All statistical analysis was performed using STATA v.11 (StataCorp, College Station, TX, USA). A 2 -sided alpha error $<0.05$ indicted statistical significance. This study was conducted in accordance with and approval of the NYU Langone Health institutional review board. 
Table 1. Distribution of population characteristics in patients with a new diagnosis of obstructive CAD in younger to middle-aged patients compared to older ones

\begin{tabular}{|c|c|c|c|}
\hline Characteristic & $\begin{array}{l}\text { Young ( } 24-57 \text { years }) \\
n=281\end{array}$ & $\begin{array}{l}\text { Old (58-96 years), } \\
n=799\end{array}$ & $p$ value \\
\hline Age, years & $50 \pm 6$ & $69 \pm 7.5$ & - \\
\hline Male sex & $228(81)$ & $567(71)$ & $<0.01$ \\
\hline Body mass index, $\mathrm{kg} / \mathrm{m}^{2}$ & $31 \pm 6$ & $29 \pm 6$ & $<0.001$ \\
\hline Hypertension & $181(64)$ & $649(81)$ & $<0.001$ \\
\hline Hypercholesterolemia & $212(76)$ & $636(80)$ & 0.15 \\
\hline Diabetes mellitus & $81(29)$ & $259(33)$ & 0.27 \\
\hline Active smoking & $60(21)$ & $69(9)$ & $<0.001$ \\
\hline Traditional CVD RF & $3.5 \pm 1.2$ & $3.5 \pm 1.1$ & 0.62 \\
\hline Family history of MI & $93(33)$ & $212(27)$ & 0.04 \\
\hline Personal stress & $61(24)$ & $109(15)$ & $<0.01$ \\
\hline Financial stress & $91(35)$ & $171(23)$ & $<0.001$ \\
\hline Depression & $25(10)$ & $72(10)$ & 0.92 \\
\hline Married & $191(69)$ & $509(66)$ & 0.33 \\
\hline Fruits and/or vegetables/day (cups) & $2.8 \pm 1.9$ & $3.0 \pm 1.8$ & 0.08 \\
\hline Aspirin & $187(66)$ & $609(76)$ & $<0.01$ \\
\hline Statin medication & $15656)$ & $539(67)$ & $<0.001$ \\
\hline Antihypertension medication & $149(52)$ & $489(61)$ & 0.10 \\
\hline Diabetes medication & $73(28)$ & $230(31)$ & 0.32 \\
\hline Systolic blood pressure, $\mathrm{mm} \mathrm{Hg}$ & $128 \pm 17$ & $132 \pm 18$ & $<0.001$ \\
\hline Diastolic blood pressure, $\mathrm{mm} \mathrm{Hg}$ & $76 \pm 10$ & $72 \pm 11$ & $<0.001$ \\
\hline Hemoglobin A1c, \% & $6.6 \pm 1.9$ & $6.4 \pm 1.3$ & 0.06 \\
\hline Total cholesterol, mg/dL & $179 \pm 67$ & $162 \pm 42$ & $<0.001$ \\
\hline $\mathrm{LDL}-\mathrm{C}, \mathrm{mg} / \mathrm{dL}$ & $102 \pm 42$ & $89 \pm 34$ & $<0.001$ \\
\hline $\mathrm{HDL}-\mathrm{C}, \mathrm{mg} / \mathrm{dL}$ & $44 \pm 25$ & $47 \pm 15$ & $<0.01$ \\
\hline Triglycerides, mg/dL & $123[90-201]$ & $112[77-166]$ & $<0.001$ \\
\hline Left main disease & $2(0.7)$ & $16(2.0)$ & 0.14 \\
\hline 1 -vessel CAD & $164(66)$ & $440(62)$ & 0.27 \\
\hline 2-vessel CAD & $66(26)$ & $216(30)$ & 0.24 \\
\hline 3-vessel CAD & $20(8.0)$ & $57(8.0)$ & 0.99 \\
\hline
\end{tabular}

Continuous variables are expressed as means \pm SD. The $t$ test was used for normally distributed continuous variables and the Mann-Whitney $U$ test for nonnormally distributed variables, which are expressed as medians [interquartile range]. Categorical variables are expressed as $n(\%)$, and the $\chi^{2}$ test was used for significance. Obstructive CAD is defined as $\geq 70 \%$ stenosis or $\geq 50 \%$ for left main disease. CAD, coronary artery disease; CVD, cardiovascular disease; MI, myocardial infarction; RF, risk factors. ${ }^{a}$ The number of CVD risk factors (male, hypertension, hyperlipidemia, overweight, active smoking, diabetes).

\section{Results}

Descriptive characteristics of the study population are listed in Table 1. Among 1,088 patients presenting with a new diagnosis of obstructive CAD, young to middleaged patients (first quartile; $50 \pm 6$ years) compared to the older three quartiles ( $69 \pm 7.5$ years) were more likely to be male, active smokers, obese, and less likely to have pre-existing HTN (Table 1; see online suppl. Table 1; for all online suppl. material, see www. karger.com/doi/10.1159/000498891). The number of traditional CVD risk factors including HLD and DM were similar in the young to middle-aged patients compared to the other three quartiles; however, younger patients had higher levels of both total and LDL cholesterol, higher diastolic and lower systolic blood pressure measurements and were less likely to be treated with aspirin and lipid-lowering (statin) therapy at the time of coronary angiography. When assessing the degree of obstructive $\mathrm{CAD}$, there was no difference in the number of ves- 
Table 2. Control of cardiovascular health factors in patients with a new diagnosis of obstructive CAD in younger to middle-aged patients compared to older ones

\begin{tabular}{lccc}
\hline CV health factors & $\begin{array}{l}\text { Young }(24-57 \text { years), } \\
n=281\end{array}$ & $\begin{array}{l}\text { Old (58-96 years), } \\
n=799\end{array}$ & $p$ value \\
\hline Body mass index $<25 \mathrm{~kg} / \mathrm{m}^{2}$ & $49(18)$ & $197(25)$ & 0.01 \\
Systolic blood pressure $<120 \mathrm{~mm} \mathrm{Hg}$ & $92(34)$ & $171(23)$ & $<0.001$ \\
Total cholesterol $<200 \mathrm{mg} / \mathrm{dL}$ & $198(71)$ & $665(84)$ & $<0.001$ \\
Non-HDL cholesterol $<130 \mathrm{mg} / \mathrm{dL}$ & $146(51)$ & $554(69)$ & $<0.001$ \\
LDL-C $<100 \mathrm{mg} / \mathrm{dL}$ & $143(53)$ & $530(67)$ & 0.16 \\
$\geq 4.5$ cups/day of fruits and/or vegetables & $54(19)$ & $185(23)$ & 0.02 \\
$\geq 1$ cup fruit/day & $184(66)$ & $562(73)$ & $<0.01$ \\
$\geq 1$ cup vegetable/day & $212(76)$ & $653(85)$ & 0.46 \\
$\geq 2$ servings of fish/week & $168(39)$ & $517(42)$ & $<0.01$ \\
$\geq 1$ serving of fish/week & $189(68)$ & $615(80)$ & $<0.01$ \\
$<8$ ounces sweetened beverages/day & $195(71)$ & $726(91)$ & 0.001 \\
Nonsmoking & $221(79)$ & $519(65)$ & 0.19 \\
Hemoglobin Alc $<7.0 \%$ & $171(60)$ & $216(33)$ & $<0.001$ \\
$\quad$ Hemoglobin Alc $<5.7 \%$ & $78(34)$ & $580(72)$ & 0.16 \\
Metabolic equivalent $\geq 85 \%$ predicted & $129(45)$ & & \\
\hline
\end{tabular}

Values are expressed as $n$ (\%). Cardiovascular health factor control was defined using the American Heart Association Life's Simple 7 recommendations. Numbers may not add up to 1,088 due to missing variables $(<5 \%$ for each group). The $t$ test was used for continuous variables and the $\chi^{2}$ test was used for categorical variables. $\mathrm{CV}$, cardiovascular; CAD, coronary artery disease.

sels affected in young to middle-aged patients compared to older ones (Table 1).

When assessing lifestyle CVD risk factors, young to middle-aged patients were more likely to have higher levels of personal and financial stress and lower functional capacity (Table 1). The dietary intake of these patients was also less optimal when compared to older patients including less fruit, vegetable, and fish intake as well as a higher proportion of sweetened beverage intake compared to older patients (Tables 1 and 2; online suppl. Table 1).

Overall, young to middle-aged patients with a new diagnosis of obstructive CAD had significantly fewer CV health factors at goal when compared to older patients (Table 2; Fig. 1). These younger patients were more likely to be overweight or obese, to be active smokers, and to have a higher blood pressure as well as higher cholesterol levels than older patients. They also had lower functional capacity compared to older patients, and a lower percentage followed the AHA recommendations for a healthy diet in terms of fruit, vegetable, fish, and sweetened beverage intake (Table 2).

In univariable analysis assessing the association between lifestyle factors and age, compared to older patients, young to middle-aged patients had a higher odds of personal stress (OR, 1.8; 95\% CI 1.3-2.5), financial stress (OR, 1.8; 95\% CI 1.3-2.4), and lower functional capacity (OR, 3.1; 95\% CI 2.4-4.1). The young to middleaged patients had higher odds of low consumption of fruit (OR, 1.7; 95\% CI 1.1-2.4), vegetables (OR, 1.9; 95\% CI 1.2-2.9), and fish (OR, $1.595 \%$ CI 1.0-2.0), as well as greater sweetened beverage intake (OR, 1.6; 95\% CI 1.22.3) (Table 3). Aside from fruit intake, these associations remained unchanged after adjustment for traditional CVD risk factors such as sex, obesity, HTN, HLD, DM, and active smoking. No interaction was noted between these lifestyle factors and sex $(p>0.05$; Table 3$)$.

\section{Discussion}

In this retrospective analysis of patients with a new diagnosis of obstructive CAD, young to middle-aged patients compared to older ones had worse dietary patterns and lower rates of controlled CV health factors including higher BMI, worse lipid measurements, and active smoking. Also noted were higher rates of CVD risk factors not accounted for in traditional CVD risk scoring systems such as personal and financial stress and low functional capacity. At the time of catheterization, compared to old-
86

Cardiology 2019;142:83-90 DOI: $10.1159 / 000498891$
Garshick/Vaidean/Vani/Underberg/

Newman/Berger/Fisher/Gianos 
Table 3. Association of lifestyle factors in patients with a new diagnosis of obstructive CAD in younger to middleaged patients compared to older ones $(n=1,088)$

\begin{tabular}{|c|c|c|c|c|}
\hline \multirow[t]{2}{*}{ Lifestyle factor } & \multicolumn{2}{|c|}{ Univariable model } & \multicolumn{2}{|c|}{ Multivariable model } \\
\hline & OR (CI) & $p$ value & $\mathrm{aOR}(\mathrm{CI})$ & $p$ value* \\
\hline Personal stress & $1.8(1.3-2.5)$ & $<0.01$ & $1.6(1.1-2.4)$ & $<0.01$ \\
\hline Financial stress & $1.8(1.3-2.4)$ & $<0.01$ & $1.8(1.3-2.5)$ & $<0.01$ \\
\hline Low functional capacity & $3.1(2.4-4.1)$ & $<0.01$ & $3.3(2.4-4.5)$ & $<0.01$ \\
\hline$<1$ cup fruit/day & $1.4(1.04-1.9)$ & 0.03 & $1.3(0.9-1.7)$ & 0.16 \\
\hline$<1$ cup vegetables/day & $1.8(1.3-2.5)$ & $<0.01$ & $1.6(1.1-2.4)$ & $<0.01$ \\
\hline$<1$ serving fish/week & $1.5(1.1-2.1)$ & $<0.01$ & $1.4(1.04-2.0)$ & 0.03 \\
\hline$\geq 8$ ounces sweetened beverages/day & $1.6(1.2-2.3)$ & $<0.01$ & $1.5(1.1-2.2)$ & 0.01 \\
\hline
\end{tabular}

The multivariable model was adjusted for sex, obesity, hypertension, hyperlipidemia, active smoking, and diabetes. Low functional capacity defined as $\leq 85 \%$ of predicted METs for age and sex. * No interaction was noted between any lifestyle factor and $\operatorname{sex}(p>0.05$ for all variables). CAD, coronary artery disease.

Fig. 1. Diagram showing controlled CV health factors in younger to middle-aged patients compared to older ones newly diagnosed with obstructive CAD. Young to middle-aged patients presenting with a new diagnosis of obstructive CAD had less CV health factors at goal compared to older ones. The mean number of CVD health factors at goal was $2.7 \pm 1.2$ in the youngest quartile and $3.0 \pm 1.0$ in the other three quartiles combined $(\mathrm{p}<0.001)$. CV health factors at goal were defined using the American Heart Association Life's Simple 7 recommendations.

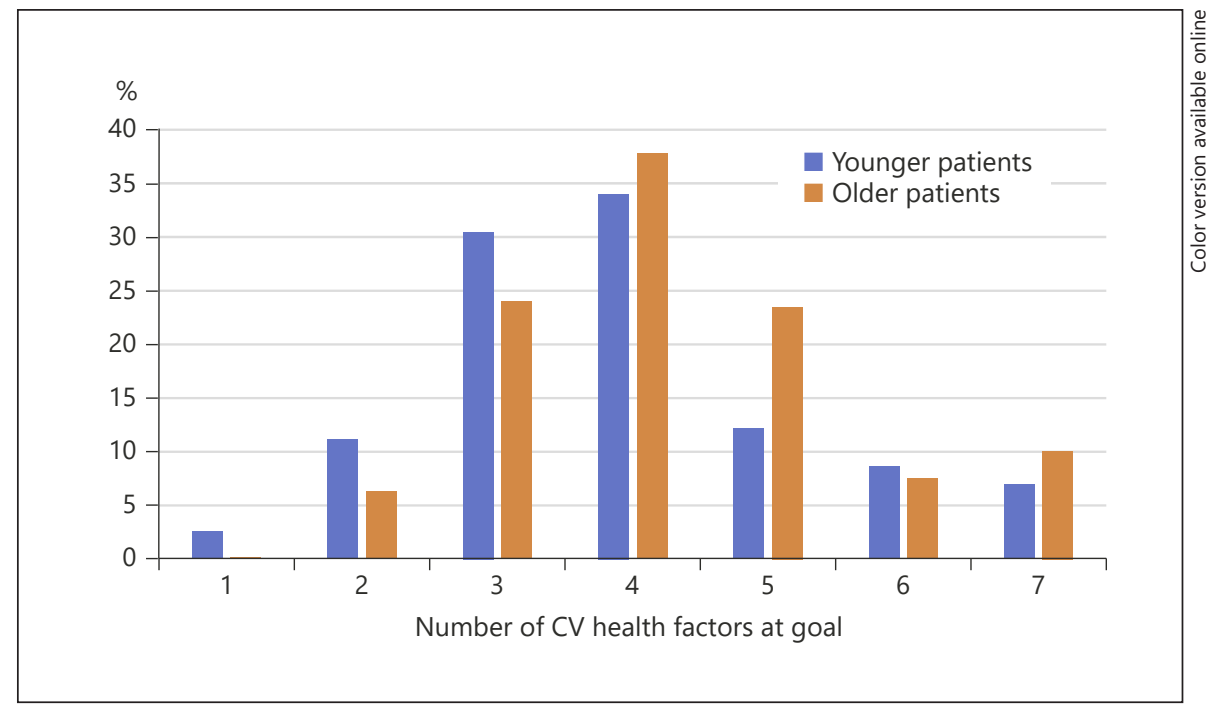

er patients, young to middle-aged patients were less frequently on aspirin and statin therapy.

Our findings, including low rates of CVD prevention therapy, are consistent with recent analysis of the YoungMI registry, where the majority of young adults presenting with an MI would not have met guideline-based criteria for prevention medications, such as statins, prior to their MI [16]. An estimated $85-90 \%$ of CVD risk is attributed to traditional CVD risk factors [17] as well as a 4-5 times increased lifetime CVD risk $[4,6,18]$. Consistent with the Young-MI registry, our analysis suggests that one potential mechanisms for CVD in the younger cohort is a potentially underrecognized CVD risk. However, based on the available data in our analysis, this observation would have to be investigated in future studies.

These young to middle-aged patients also had a significantly poorer $\mathrm{CV}$ health factor control as defined by AHA guideline recommendations [15]. This suggests that in addition to traditional CVD risk factor recognition and treatment, a focus on lifestyle factors which are upstream in the causal pathway of CVD may guide more effective preventive counseling, particularly in younger individuals [19]. For example, we found that failure to attain a healthy lifestyle significantly correlated with obstructive $\mathrm{CAD}$ at a younger age. Self-reported adherence to a healthy diet of fruits, vegetables, and fish intake was sig- 
nificantly less in the young to middle-aged compared to older patient cohort. These younger patients also had a notably low functional capacity, a significant concern as these findings correlate with poor health and risk for poor outcomes [14, 20].

The increased level of perceived personal and financial stress noted in the younger cohort is also of interest. Studies have previously noted the connection between stress and CVD [21]. Stress has been linked to lower levels of physical activity, smoking, and CV medication adherence which may explain the association with CVD [22]. Biologically, stress has also been linked to systemic inflammatory processes which may influence the pathogenesis of atherosclerosis [22, 23]. Finally, how age influences the relationship between psychosocial factors and CVD has remained unclear $[24,25]$. Our study builds on previous studies by finding that both perceived financial and personal stress was preferentially associated with CAD at a younger age $[26,27]$.

In our analysis, we also noted elevated diastolic and lower systolic blood pressure measurements in the young to middle-aged compared to older patient population. Given the real-world setting of our prevention registry where blood pressure was measured post cardiac catheterization, it is unclear what the significance of these findings are. National Health and Nutrition Examination Survey (NHANES) data have shown a higher prevalence of untreated isolated diastolic HTN in middle-aged compared to older adults, where as expected, isolated systolic HTN was highest in older individuals [28]. Expanding on this, analysis of young adults with HTN over a follow-up of more than 20 years, men (who make up the majority of our registry) with a diagnosis of isolated diastolic HTN had a similar incidence of CVD mortality when compared to systolic-diastolic HTN and a higher incidence of CVD mortality compared to isolated systolic HTN [29]. Our findings of higher diastolic and lower systolic blood pressure in the young to middle-aged cohort should be further investigated in studies assessing CVD risk in younger populations.

Overall, favorable traditional and lifestyle CVD risk factor control is important as it can have lasting impact, potentially reducing the incidence of CVD [30]. The World Health Organization (WHO) has recognized the need for optimal CVD risk factor control, having set worldwide goals of reduced premature CVD mortality (defined as between 30-70 years of age) [31]. Predictive models by the WHO reveal that CVD deaths can be reduced by $25 \%$ through recognition and improvement of CVD risk factors such as HTN, DM, HLD, obesity, smok- ing, and physical inactivity [31]. For example, studies such as the Coronary Artery Risk Development in Young Adults (CARDIA) have noted that healthy lifestyle changes at the age of 20 years were correlated with reduced odds of atherosclerosis 30 years later [32].

Building on this concept of lifetime CVD risk reduction strategies, the findings of suboptimal CVD risk factor control and lack of CV health factors at goal in the younger cohort have implications for the lifetime CVD risk as poor lifestyle choices are compounded over time [33]. It also represents an opportunity to further modify risk among young to middle-age patients to improve adverse health outcomes [34]. Specifically, our study helps inform preventive counseling efforts in younger middleaged adults, especially since traditional CVD risk factors often underestimate the 10 -year CVD risk in these individuals [5].

Our study has several limitations. First, this was a cross-sectional analysis and we can therefore only assess association and not causation. Our sample represents a patient population at a single, major medical center targeted for cardiac prevention counseling with reasons for cardiac catheterization referral unknown. Our study population was also predominantly male and Caucasian, a feature which may limit the external validity. Additionally, we used self-administered dietary surveys based on AHA heart healthy recommendations and therefore the dietary responses may not have been as accurate as other validated food frequency questionnaires. Finally, questions on depression and psychosocial well-being were carried out as part of clinical care as opposed to a research environment. While this may not be sufficient for an indepth etiologic exploration of psychosocial stressors, it illustrates a particular CVD risk factor profile and raises awareness of the potential value of further CVD risk assessment in the young to middle-aged population. The strengths of our study are that we assessed a large number of patients and we used an angiographically confirmed new diagnosis of obstructive CAD in order to specifically understand the associations of various factors with an earlier onset of obstructive CAD.

\section{Conclusion}

In summary, we found that young to middle-aged patients compared to older ones with a new diagnosis of obstructive CAD had less well-controlled CVD risk factors in addition to worse diet, more stress, and lower functional capacity. The associations noted in this analy-
88

Cardiology 2019;142:83-90 DOI: $10.1159 / 000498891$
Garshick/Vaidean/Vani/Underberg/

Newman/Berger/Fisher/Gianos 
sis build on previous studies exploring CVD risk factors and risk factor control in the young and highlight the need for investigations to determine if targeting each will improve CVD risk specifically in the young to middleaged population. Considering that existing risk prediction tools are suboptimal in the young, perhaps a traditional risk calculator combined with a lifestyle assessment can improve risk prediction and uncover opportunities for preventive measures in this population.

\section{Statement of Ethics}

The study protocol was approved by the NYU Langone Health institutional review board. The authors have no ethical conflicts to disclose. This study was conducted ethically in accordance with the Declaration of Helsinki.

\section{Disclosure Statement}

All authors declare that there are no potential conflicts of interest related to this study.

\section{Funding Sources}

This study was funded in part by a National Institutes of Health (NIH, Bethesda, MD, USA) training grant T32HL098129, Glorney-Raisbeck Research Fellowship (New York, NY, USA), and American Heart Association Career Development Grant 18CDA34080540 (Dallas, TX, USA), all awarded to M.S.G.

\section{Author Contributions}

M.S.G., G.V., and E.G. were responsible for initial study design, statistical analysis, and manuscript preparation. A.V., J.U., J.D.N., J.S.B., and E.F. were responsible for critical insight during study design and manuscript revisions.

\section{References}

1 Benjamin EJ, Virani SS, Callaway CW, Chamberlain AM, Chang AR, Cheng S, et al.; American Heart Association Council on Epidemiology and Prevention Statistics Committee and Stroke Statistics Subcommittee. Heart Disease and Stroke Statistics-2018 Update: A Report From the American Heart Association. Circulation. 2018 Mar;137(12):e67-492.

2 Sidney S, Quesenberry CP Jr, Jaffe MG, Sorel M, Nguyen-Huynh MN, Kushi LH, et al. Recent Trends in Cardiovascular Mortality in the United States and Public Health Goals. JAMA Cardiol. 2016 Aug;1(5):594-9.

3 Gupta A, Wang Y, Spertus JA, Geda M, Lorenze $\mathrm{N}$, Nkonde-Price $\mathrm{C}$, et al. Trends in acute myocardial infarction in young patients and differences by sex and race, 2001 to 2010. J Am Coll Cardiol. 2014 Jul;64(4):337-45.

4 Andersson C, Vasan RS. Epidemiology of cardiovascular disease in young individuals. Nat Rev Cardiol. 2018 Apr;15(4):230-40.

5 Hobbs FD, Jukema JW, Da Silva PM, McCormack T, Catapano AL. Barriers to cardiovascular disease risk scoring and primary prevention in Europe. QJM. 2010 Oct;103(10): 727-39.

6 Lloyd-Jones DM. Cardiovascular risk prediction: basic concepts, current status, and future directions. Circulation. 2010 Apr;121(15): 1768-77.

7 Jacobson TA, Ito MK, Maki KC, Orringer CE, Bays HE, Jones PH, et al. National lipid association recommendations for patient-centered management of dyslipidemia: part 1full report. J Clin Lipidol. 2015 Mar-Apr;9(2): $129-69$.
8 Jacobson TA, Maki KC, Orringer CE, Jones PH, Kris-Etherton P, Sikand G, et al.: National Lipid Association Recommendations for Patient-Centered Management of Dyslipidemia: Part 2. J Clin Lipidol. 2015 Nov-Dec; 9(6 Suppl):S1-122.e1.

9 Bibbins-Domingo K, Grossman DC, Curry SJ, Davidson KW, Epling JW Jr, García FA, et al.; US Preventive Services Task Force. Statin Use for the Primary Prevention of Cardiovascular Disease in Adults: US Preventive Services Task Force Recommendation Statement. JAMA. 2016 Nov;316(19):1997-2007.

10 Stone NJ, Robinson JG, Lichtenstein $\mathrm{AH}$, Bairey Merz CN, Blum CB, Eckel RH, et al.; American College of Cardiology/American Heart Association Task Force on Practice Guidelines. 2013 ACC/AHA guideline on the treatment of blood cholesterol to reduce atherosclerotic cardiovascular risk in adults: a report of the American College of Cardiology/ American Heart Association Task Force on Practice Guidelines. J Am Coll Cardiol. 2014 Jul;63(25 25 Pt B):2889-934.

11 Tully L, Gianos E, Vani A, Guo Y, Balakrishnan R, Schwartzbard A, et al.: Suboptimal risk factor control in patients undergoing elective coronary or peripheral percutaneous intervention. Am Heart J. 2014;168(3):310-6 e3. https://doi.org/10.1016/j.ahj.2014.05.011.

12 Balakrishnan R, Berger JS, Tully L, Vani A, Shah B, Burdowski J, et al. Prevalence of unrecognized diabetes, prediabetes and metabolic syndrome in patients undergoing elective percutaneous coronary intervention. $\mathrm{Di}$ abetes Metab Res Rev. 2015 Sep;31(6):603-9.
13 Lloyd-Jones DM, Hong Y, Labarthe D, Mozaffarian D, Appel LJ, Van Horn L, et al.; American Heart Association Strategic Planning Task Force and Statistics Committee. Defining and setting national goals for cardiovascular health promotion and disease reduction: the American Heart Association's strategic Impact Goal through 2020 and beyond. Circulation. 2010 Feb;121(4):586-613.

14 Hlatky MA, Boineau RE, Higginbotham MB Lee KL, Mark DB, Califf RM, et al. A brief selfadministered questionnaire to determine functional capacity (the Duke Activity Status Index). Am J Cardiol. 1989 Sep;64(10):651-4.

15 Eckel RH, Jakicic JM, Ard JD, de Jesus JM, Houston Miller N, Hubbard VS, et al.; American College of Cardiology/American Heart Association Task Force on Practice Guidelines. 2013 AHA/ACC guideline on lifestyle management to reduce cardiovascular risk: a report of the American College of Cardiology/American Heart Association Task Force on Practice Guidelines. J Am Coll Cardiol. 2014 Jul;63(25 25 Pt B):2960-84.

16 Singh A, Collins BL, Gupta A, Fatima A, Qamar A, Biery D, et al. Cardiovascular Risk and Statin Eligibility of Young Adults After an MI: partners YOUNG-MI Registry. J Am Coll Cardiol. 2018 Jan;71(3):292-302.

17 Aggarwal A, Srivastava S, Velmurugan M. Newer perspectives of coronary artery disease in young. World J Cardiol. 2016 Dec;8(12): $728-34$.
Obstructive Coronary Artery Disease in Young to Middle-Aged Patients
Cardiology 2019;142:83-90 DOI: $10.1159 / 000498891$ 
18 Pletcher MJ, Vittinghoff E, Thanataveerat A, Bibbins-Domingo K, Moran AE. Young Adult Exposure to Cardiovascular Risk Factors and Risk of Events Later in Life: The Framingham Offspring Study. PLoS One. 2016 May;11(5):e0154288.

19 Lévesque V, Poirier P, Després JP, Alméras N. Relation Between a Simple Lifestyle Risk Score and Established Biological Risk Factors for Cardiovascular Disease. Am J Cardiol. 2017 Dec;120(11):1939-46.

20 Tang WH, Topol EJ, Fan Y, Wu Y, Cho L, Stevenson C, et al. Prognostic value of estimated functional capacity incremental to cardiac biomarkers in stable cardiac patients. J Am Heart Assoc. 2014 Oct;3(5):e000960.

21 Dimsdale JE. Psychological stress and cardiovascular disease. J Am Coll Cardiol. 2008 Apr; 51(13):1237-46.

22 Cohen BE, Edmondson D, Kronish IM. State of the Art Review: Depression, Stress, Anxiety, and Cardiovascular Disease. Am J Hypertens. 2015 Nov;28(11):1295-302.

23 Hamer M, Endrighi R, Venuraju SM, Lahiri A, Steptoe A. Cortisol responses to mental stress and the progression of coronary artery calcification in healthy men and women. PLoS One. 2012;7(2):e31356.

24 Yusuf S, Hawken S, Ounpuu S, Dans T, Avezum A, Lanas F, et al.; INTERHEART Study Investigators. Effect of potentially modifiable risk factors associated with myocardial infarction in 52 countries (the INTERHEART study): case-control study. Lancet. 2004 Sep; 364(9438):937-52.
25 Yan LL, Liu K, Matthews KA, Daviglus ML, Ferguson TF, Kiefe CI. Psychosocial factors and risk of hypertension: the Coronary Artery Risk Development in Young Adults (CARDIA) study. JAMA. 2003 Oct;290(16):213848.

26 Iribarren C, Sidney S, Bild DE, Liu K, Markovitz JH, Roseman JM, et al. Association of hostility with coronary artery calcification in young adults: the CARDIA study. Coronary Artery Risk Development in Young Adults. JAMA. 2000 May;283(19):2546-51.

27 Cole JH, Sperling LS. Premature coronary artery disease: clinical risk factors and prognosis. Curr Atheroscler Rep. 2004 Mar;6(2): 121-5.

28 Franklin SS, Jacobs MJ, Wong ND, L'Italien GJ, Lapuerta P. Predominance of isolated systolic hypertension among middle-aged and elderly US hypertensives: analysis based on National Health and Nutrition Examination Survey (NHANES) III. Hypertension. 2001 Mar;37(3):869-74.

29 Yano Y, Stamler J, Garside DB, Daviglus ML, Franklin SS, Carnethon MR, et al. Isolated systolic hypertension in young and middleaged adults and 31-year risk for cardiovascular mortality: the Chicago Heart Association Detection Project in Industry study. J Am Coll Cardiol. 2015 Feb;65(4):327-35.

30 Greenland P, Fuster V. Cardiovascular Risk Factor Control for All. JAMA. 2017 Jul; 318(2):130-1.
31 Sacco RL, Roth GA, Reddy KS, Arnett DK, Bonita R, Gaziano TA, et al. The Heart of 25 by 25: Achieving the Goal of Reducing Global and Regional Premature Deaths From Cardiovascular Diseases and Stroke: A Modeling Study From the American Heart Association and World Heart Federation. Glob Heart. 2016 Jun;11(2):251-64.

32 Spring B, Moller AC, Colangelo LA, Siddique J, Roehrig M, Daviglus ML, et al. Healthy lifestyle change and subclinical atherosclerosis in young adults: Coronary Artery Risk Development in Young Adults (CARDIA) study. Circulation. 2014 Jul;130(1):10-7.

33 Movassagh EZ, Baxter-Jones AD, Kontulainen S, Whiting SJ, Vatanparast H. Tracking Dietary Patterns over 20 Years from Childhood through Adolescence into Young Adulthood: The Saskatchewan Pediatric Bone Mineral Accrual Study. Nutrients. 2017 Sep;9(9):E990.

34 Hivert MF, Arena R, Forman DE, Kris-Etherton PM, McBride PE, Pate RR, et al.; American Heart Association Physical Activity Committee of the Council on Lifestyle and Cardiometabolic Health; the Behavior Change Committee, a joint committee of the Council on Lifestyle and Cardiometabolic Health and the Council on Epidemiology and Prevention; the Exercise, Cardiac Rehabilitation, and Secondary Prevention Committee of the Council on Clinical Cardiology; and the Council on Cardiovascular and Stroke Nursing. Medical Training to Achieve Competency in Lifestyle Counseling: An Essential Foundation for Prevention and Treatment of Cardiovascular Diseases and Other Chronic Medical Conditions: A Scientific Statement From the American Heart Association. Circulation. 2016 Oct;134(15):e308-27. 